Ensino, Saúde e Ambiente - V9 (1), pp. 77-89, Abril, 2016.

\title{
FORMAÇÃO DE CONCEITOS, ENSINO, APRENDIZAGEM E DESENVOLVIMENTO NA PERSPECTIVA HISTÓRICO-CULTURAL
}

\author{
CONCEPTS CREATION, TEACHING, LEARNING AND DEVELOPMENT ON \\ THE HISTORICAL AND CULTURAL THEORY \\ BAMPI, Maria Luisa Furlin ${ }^{1}$, SCHINDHELM, Virginia Georg ${ }^{2}$ \\ ${ }^{1}$ FAFIMA - Faculdade de Filosofia, Ciências e Letras de Macaé, luisa.bampi@ uol.com.br \\ ${ }^{2}$ UFF - Universidade Federal Fluminense/Faculdade de Educação, Departamento de Fundamentos \\ Pedagógicos \\ SEFLU Sociedade Educacional Fluminense, Faculdade de Psicologia, psicovir@terra.com.br
}

\begin{abstract}
RESUMO
Este artigo teórico-reflexivo analisa uma experiência cotidiana e a significação de alguns conceitos envolvendo conhecimentos espontâneos e científicos construídos por duas crianças da Educação Infantil e uma pesquisadora durante sua investigação de doutoramento. A partir das concepções construídas por crianças e adultos, discutimos a relação que se estabelece entre a formação de conceitos espontâneos e científicos no processo de organização do psiquismo e constituição social do sujeito, numa perspectiva histórico-cultural. Buscamos ainda refletir sobre: (a) como se estabelece a inter-relação contínua e indissociável entre o aprendizado e desenvolvimento na construção do conhecimento; (b) qual a importância da aprendizagem e do desenvolvimento no espaço escolar (c) como a cultura e a linguagem colaboram na construção subjetiva de conceitos. Para tanto, pretendemos analisar os princípios vigotskianos essenciais do trabalho docente no cotidiano da Educação Infantil capaz de impulsionar o processo de desenvolvimento humano, através deles confirmamos a necessidade de promover, organizar, sistematizar e consolidar práticas pedagógicas mediadoras das relações entre as crianças com a cultura ou os conhecimentos científicos uma vez que a aprendizagem promove as diferentes dimensões do desenvolvimento humano. Evidenciamos que os conceitos científicos são negociados culturalmente e apresentam-se como resultado de uma construção iniciada por conceitos espontâneos. Confirmamos que existe uma unidade no processo de ensinar/aprender, tal como postulado por Vigotski pela expressão russa obutchenie.
\end{abstract}

Palavras-chave: aprendizagem; desenvolvimento; abordagem histórico-cultural.

\begin{abstract}
This theoretical and reflexive article analyses an everyday experience and some concepts meanings which envolve spontaneous and scientific understanding made by two pre-school children and a researcher during her doctorate degree investigation. As from the conceptions made by the children and adults we discuss the relationship established between the scientific and spontaneous concepts creation in the process of psychism organization and the man's social constitution in a historical and cultural theory. We still reflect about: (a) how the continuous interelationship between the learning and the understanding development construction is established; (b) the
\end{abstract}


importance of learning and the development in the school place; (c) how culture and language work together in the subjective concepts building. For this purpose we intend to analyse Vigotski's principles which are essential for the everyday pre school teaching work and is able to encourage the human development process and according to them we assure the necessity of organizing, ordering and establishing pedagogical practices which will serve to mediate the relationship between the children and the culture or the scientific understanding whereas the learning process raises different extensions in the human development. We make clear that the scientific concepts are culturally dealt and presented as a result of a construction which started by spontaneous concepts. There is a unity in the teaching/learning process assumed by Vigotsky by the russian expression obutchenie.

Keywords: learning, development, historical and cultural theory

\section{INTRODUÇÃO}

"Chovera muito no fim de semana e hoje (segunda-feira) deparei-me com três grandes cogumelos brancos que nasceram no gramado da creche onde me inseri para a pesquisa de meu doutoramento. Observando os cogumelos aproximou-se um menino (2 anos) perguntando: o que é isso? São cogumelos, respondi sem perceber a presença de outro garoto maior (5 anos) atrás de mim. Este rapidamente declarou: não são não, cogumelos são vermelhos com bolinhas brancas e foi embora. $\mathrm{O}$ pequeno também foi embora e eu fiquei refletindo sobre nossos conhecimentos acerca de cogumelos brancos ou vermelhos com bolinhas brancas" (nota de campo, 2010).

Destacamos essa situação cotidiana na Educação Infantil para refletirmos acerca da construção dos conhecimentos espontâneos e científicos desde a infância, de modo a entender as habilidades cognitivas entrelaçadas pelas invenções culturais, tais como as de memória, raciocínio e solução de problemas, dentre tantas outras.

Ressaltamos, no entanto, que pensar sobre a construção de conhecimentos implica primeiramente em considerarmos as relações entre os campos da Psicologia, da Educação e da Cultura na contemporaneidade, na medida em que, numa sociedade do conhecimento, a escolarização tem um valor inquestionável porque proporciona ao sujeito experiências e informações de sua cultura. De acordo com Rego (2002) o acesso do sujeito à escola significa uma apropriação do saber sistematizado de instrumentos de atuação no meio social e de condições para a construção de conhecimentos.

No entanto, isto não significa que a apropriação subjetiva de um legado do seu grupo cultural ocorra somente quando a criança entra para a escola. Aprender é um aspecto necessário e universal que se destaca como uma espécie de garantia do 
Ensino, Saúde e Ambiente - V9 (1), pp. 77-89, Abril, 2016.

desenvolvimento das características psicológicas especificamente humanas e culturalmente organizadas, como nos ensina a abordagem histórico-cultural, uma das concepções interacionistas por meio da qual apoiamos as reflexões destacadas para discutirmos nesse artigo.

De acordo com Davis e Oliveira (2010), numa visão interacionista, o sujeito constrói os seus conhecimentos por meio de sua interação com o meio, onde ambos exercem ação recíproca. Os fatores internos e externos se inter-relacionam continuamente e, nessa interação de influência de um sobre outro, ocorrem mudanças sobre o sujeito.

Nesse sentido, partimos do pressuposto de que a relação entre desenvolvimento e aprendizagem implica no reconhecimento de que o aprendizado é um processo fundamental para a construção do ser humano e que o desenvolvimento do sujeito baseia-se num aprender que envolve não apenas a interferência direta ou indireta de outros indivíduos, todavia uma fluida e constante reconstrução pessoal de experiências e seus significados vivenciados num determinado contexto histórico e sociocultural.

Assim sendo, elegemos discutir nesse artigo as relações entre aprendizagem e desenvolvimento, entendendo o desenvolvimento como um estudo dos processos de transformação e estabilidade em todos os domínios ou aspectos ao longo do ciclo de vida humano (PAPALIA, FELDMAN, 2013).

Organizamos nossas reflexões em três seções: na primeira destacamos os conceitos espontâneos e científicos para refletirmos sobre a inter-relação que se estabelece entre o aprendizado e o conhecimento.

$\mathrm{Na}$ segunda seção discorremos sobre a relação contínua e indissociável da aprendizagem e do desenvolvimento e sua importância no espaço escolar, pois segundo os aportes da teoria vigotskiana, a aprendizagem antecede, amplia e possibilita o processo de desenvolvimento.

$\mathrm{Na}$ terceira seção finalizamos o artigo refletindo sobre a relação da cultura e da linguagem na construção dos conceitos espontâneos e científicos e suas implicações em nosso estudo.

\section{CONCEITOS ESPONTÂNEOS E CONCEITOS CIENTÍFICOS}

Retomamos a experiência cotidiana relativa aos cogumelos brancos, que para a criança só seriam cogumelos se fossem vermelhos com bolinhas brancas para o destacarmos como nosso exemplo empírico e pensarmos acerca das diferenças entre o 


\section{Ensino, Saúde e Ambiente - V9 (1), pp. 77-89, Abril, 2016.}

que seria um conhecimento ou conceito espontâneo e um conhecimento ou conceito científico.

Vigotski postulou que os conceitos espontâneos e científicos referem-se a processos diferentes, ou seja, não são itens conceituais que, por si, seriam enquadrados numa ou noutra classe.

Os conceitos espontâneos de uma criança vinculam-se ao sensorial de cuja percepção e elaboração ele surge, por isso, podem ser entendidos como aqueles que emergem das reflexões da própria criança sobre a experiência cotidiana. Desenvolvidos no decorrer da vida diária e prática da criança, de suas interações imediatas, poderíamos afirmar são sempre impregnados de experiência no enfrentamento com as coisas.

Além disso, os conhecimentos espontâneos são elaborados nas situações de utilização da linguagem, apesar da criança não ter consciência deles, na medida em que se centra nos objetos a que se referem e não no seu próprio ato de pensamento. Ela usa adequadamente a palavra, todavia não consegue ainda utilizá-la com consciência e deliberação, por ser incapaz de elevar-se acima do significado situacional da palavra.

Dessa forma, ao lidar com conceitos do cotidiano, a criança comumente entra em contradição ao pensar sobre eles, porque ainda não os considera no plano das abstrações.

Segundo Jobim e Souza e Kramer (1991, p. 79) o desenvolvimento dos conceitos espontâneos pode ser considerado como ascendente por forçar os conceitos cotidianos "para cima" abrindo caminho para os conceitos científicos.

Os conhecimentos científicos são conceitos logicamente definidos e formalizados, frutos de acordos culturais porque se originam de atividades estruturadas, organizados em sistemas inter-relacionais e adquiridos por meio do ensino formal com a ajuda de um Outro social. Jobim e Souza e Kramer (1991, p. 79) afirmam que o desenvolvimento do conceito científico é descendente, desenvolvem-se "para baixo" fornecendo as estruturas para o desenvolvimento ascendente dos conceitos espontâneos.

Isto significa que os conceitos científicos tornam-se acessíveis principalmente nas relações escolarizadas, pela mediação deliberada e explícita de alguém mais experiente que possibilite a aquisição de conhecimentos sistematizados para a criança. Nesse sentido, a intervenção pedagógica torna-se fundamental para o desenvolvimento dos conceitos científicos, na medida em que demandam a elaboração de operações lógicas complexas, que ainda não são dominadas pela criança. Podemos assim dizer que os conceitos científicos provocam avanços nas funções psicológicas superiores que não 


\section{Ensino, Saúde e Ambiente - V9 (1), pp. 77-89, Abril, 2016.}

ocorreriam espontaneamente na criança, pois aprender conceitos sistematizados na escola transforma todo o processo de elaboração conceitual, afetando, inclusive, os conceitos cotidianos, por acrescentar-lhes sistematicidade e também reflexividade.

Frente a essas questões, vemos que os processos de aprendizado dos conceitos espontâneos e científicos diferem, todavia correm em paralelo, pois se afetam mutuamente durante o desenvolvimento. Ambos implicam atitudes distintas em relação ao objeto. Os conceitos científicos, no início de seu desenvolvimento, são esquemáticos e desprovidos da riqueza advinda da experiência, ganham vitalidade e concretude na relação com os conceitos espontâneos.

Destacamos essas questões acerca da compreensão de como se desenvolvem os conhecimentos cotidianos (espontâneos) e os conhecimentos científicos para refletirmos também sobre as relações que estabelecem com a compreensão teórica do aprendizado e desenvolvimento.

\section{A RELAÇÃo CONTÍNUA E INDISSOCIÁVEL DA APRENDIZAGEM E DO DESENVOLVIMENTO}

Vigotski (1991, p. 80) propõe pensar a inter-relação entre os conceitos científicos e os espontâneos de forma mais ampla abarcando o aprendizado escolar no processo de desenvolvimento mental da criança. Tal proposta propõe uma inversão nas tradições filosóficas e nos pressupostos de aprendizagem e desenvolvimento humano. A grande contribuição é a ênfase na interação com o meio, nele abarcando a cultura e a concepção de ser humano enquanto um ser que atua e modifica esse meio, com propostas de saltos no desenvolvimento e de uma ruptura com o paradigma da maturação como motor do desenvolvimento, daí como assinala Silva (2015, p.32) “a importância de um novo olhar nas interações sociais (aluno-professor e aluno-aluno) no contexto escolar".

O novo olhar é uma quebra de paradigma sobre o desenvolvimento e aprendizagem da proposta vigotskiana e evidencia-se na preocupação com o permanente estado de movimento e mudança dos processos psicológicos, bem como da rejeição às noções de mudanças evolucionárias, caracterizadas pela periodicidade e linearidade. Essa nova direção de olhar volta-se para a construção de um saber partilhado, estabelecido através de relações caracterizadas pela heterogeneidade aos diferentes ritmos, trajetórias de vida, valores e conhecimentos de cada um que imprimem as 
Ensino, Saúde e Ambiente - V9 (1), pp. 77-89, Abril, 2016.

possibilidades de trocas, confrontos e apoios mútuos que ampliam as capacidades, a dialogicidade, a experiência e a aprendizagem.

Nessa perspectiva, o aprendizado é que amplia e possibilita o processo de desenvolvimento. Há aqui uma distinção, pois para Vigotski a maturação vem a reboque do desenvolvimento e, nesse sentido, a escola deveria adiantar-se ao desenvolvimento dos sujeitos e não esperar atingirem "determinada" maturação para aprender. Segundo ele, o bom aprendizado é o que se adianta ao desenvolvimento. Isso revoluciona a maneira de ensinar e aprender.

Para elucidar tal paradoxo entre a aprendizagem e o desenvolvimento humano Vigotski (1991) introduz em seus estudos dois níveis de desenvolvimento: o nível de desenvolvimento real e o nível de desenvolvimento potencial. Partindo desses dois níveis elabora o conceito de uma Zona de Desenvolvimento Proximal (ZDP).

Vale destacarmos nesse momento que, segundo Prestes (2012, p. 204), a tradução mais adequada para o termo zona blijaichego razvitia escrito por Vigotski e mais conhecida na tradução de diversos trabalhos do autor na literatura brasileira seria

[...] zona de desenvolvimento iminente, pois sua característica essencial é a das possibilidades de desenvolvimento, mais do que do imediatismo e da obrigatoriedade de ocorrência, pois se a criança não tiver a possibilidade de contar com a colaboração de outra pessoa em determinados períodos de sua vida, poderá não amadurecer certas funções intelectuais e, mesmo tendo essa pessoa, isso não garante, por si só, o seu amadurecimento.

O desenvolvimento real, também expresso por Vigotski como desenvolvimento atual, refere-se ao nível do desenvolvimento que a criança resolve as questões sozinha, ou melhor, ao nível de desenvolvimento efetivo da criança (PRESTES, 2012, p. 206). Este nível diz respeito às funções mentais ou aos ciclos de desenvolvimentos já completados ou ainda aos conhecimentos infantis já adquiridos; isto é, tudo aquilo que a criança é capaz de fazer sozinha, de forma independente. Partindo do pressuposto que a criança ao ingressar na escola já tem um repertório amplo de conhecimentos ou ainda quando avaliamos os conhecimentos com testes de inteligência, estamos determinando esse conhecimento, também chamado de zona de desenvolvimento real.

Já o desenvolvimento potencial corresponde ao que está próximo de acontecer, o seu potencial, ao nível de desenvolvimento possível da criança, aos conhecimentos que ela evidencia a partir da resolução de problemas que resolve sob a orientação ou com auxílio dos adultos e em colaboração com companheiros mais capazes (VIGOTSKI, 2007). 
Ensino, Saúde e Ambiente - V9 (1), pp. 77-89, Abril, 2016.

A distância entre o desenvolvimento real - aquilo que consegue fazer sozinha com o desenvolvimento potencial - aquilo que faz com ajuda - é chamada Zona de Desenvolvimento Proximal ou Iminente. Isso revela, no entanto, o que a criança pode desenvolver, suas possibilidades, todavia "não significa que irá obrigatoriamente desenvolver" conforme afirma Prestes (2012, p. 179)

Essa questão coloca em pauta uma área do desenvolvimento que está em processo de amadurecimento a ser acrescentado e atualizado na história do desenvolvimento da criança, pois indica um processo que está além do real, também chamado por Vigotski, os "brotos" de desenvolvimento (ibidem, p. 98).

A definição do autor apresenta o nível de desenvolvimento real num plano de tempo retrospectivo e o desenvolvimento proximal num plano futuro ou também chamado de prospectivo. Ou seja, o desenvolvimento real refere-se às funções já amadurecidas e o desenvolvimento potencial diz respeito a um conjunto de funções que estão em processo de maturação, em fase embrionária, manifestam-se a partir da interação ou com a mediação do Outro. Assim, o contato com outras pessoas, com os conhecimentos culturalmente organizados e sistematizados - com os conhecimentos científicos - é de fundamental importância para a aprendizagem, por conseguinte, para o desenvolvimento.

Outra questão a ser pontuada é que ao se avaliar o desenvolvimento da criança, a proposta é ir além daquilo que a criança apresenta como resultado, saber qual o potencial de desenvolvimento através da Zona de Desenvolvimento Iminente, aquilo que a criança consegue fazer além do que faria sozinha, mas com a mediação.

Nossas reflexões frente a esses postulados vigotskianos, sobre os quais ora dissertamos, levam-nos ainda a resgatar a importância da linguagem e da cultura na construção dos conhecimentos espontâneos e científicos da criança. Assim sendo, destacamos essa questão a seguir.

\section{CULTURA E LINGUAGEM NA CONSTRUÇÃO DOS CONCEITOS ESPONTÂNEOS E CIENTÍFICOS}

Ao retomarmos a cena da nossa experiência dos cogumelos brancos ocorrida com as duas crianças, podemos destacar que os conhecimentos construídos e narrados pela criança maior revelam um dado interessante: Quem de nós não lembrou rapidamente a imagem de cogumelos vermelhos com bolinhas brancas? Provavelmente um conhecimento culturalmente construído através da linguagem dos signos gráficos 


\section{Ensino, Saúde e Ambiente - V9 (1), pp. 77-89, Abril, 2016.}

dos contos infantis, presentes em imagens veiculadas nas decorações e atividades das escolas.

Essa reflexão evidencia a ocorrência da aprendizagem através de um processo de internalização de um conceito construído socialmente, como acima abordado na formação dos conceitos. Diante disso ressaltamos o postulado de Vigotski (2007, p. 100) quando anuncia que "o aprendizado humano pressupõe uma natureza social específica e um processo através do qual as crianças penetram na vida intelectual daqueles que as cercam".

As evidências são de que ambas as crianças aprenderam nas interações sociais e através da cultura, estando aprendizagem e desenvolvimento intrinsecamente relacionados. Além disso, a aprendizagem apareceu primeiramente no âmbito social, para depois tornar-se individual, pela internalização do signo gráfico/linguístico. Nesse caso, a internalização de um conceito já construído, talvez espontâneo, acrescido do conceito apresentado pela nossa mediação, por uma renegociação de sentido e uma reconstrução interna a partir desse novo sentido dado. A disciplina formal dos conceitos científicos transforma gradualmente a estrutura dos conceitos espontâneos da criança e ajuda a organizá-los num sistema: isso promove a ascensão da criança a níveis mais elevados do desenvolvimento (VIGOTSKI, 1991, p.100).

Portanto, estamos diante de um exemplo de formação de conceitos como processo, social, mediado pelo Outro e através da palavra. Ao fazermos referência ao uso da palavra na construção de conceitos pela mediação torna-se necessário abordar um dos principais conceitos trabalhados por Vigotski (1991), a linguagem/palavra enquanto função superior da mente. Para tal faz-se evidente a relação entre a palavra e o pensamento na constituição humana.

O autor realiza amplo estudo no campo da linguagem com destaque para a estreita relação entre o pensamento e a palavra. Segundo Vigotski (1991) pensamento e palavra teriam raízes genéticas diferentes, mas nos anos iniciais do desenvolvimento psíquico da criança vão se desenvolvendo, passando por transformações e se tornando interdependentes.

O processo de construção da palavra necessariamente passa pelo social, nascemos em um mundo em que a linguagem já está presente, implica que primeiramente há a aquisição da fala socializada, que comunica, sendo internalizada e tornando-se individualizada. Assim, a fala evolui de um plano externo ou interpsicológico para um plano interno ou intrapsicológico. 


\section{Ensino, Saúde e Ambiente - V9 (1), pp. 77-89, Abril, 2016.}

Nessa mesma perspectiva, Oliveira (1995) assinala que a trajetória do desenvolvimento humano ocorre de "fora para dentro" através da internalização, por processos interpsicológicos. Tal evolução não existiria no ser humano fora de um grupo cultural específico. Essa ideia se evidencia no fato de que um ser humano que passe toda sua vida no interior de um grupo cultural ágrafo, por exemplo, jamais seria alfabetizado, ainda que de posse de todo o aparato físico da espécie que lhe possibilite o aprendizado da escrita. Ele só aprenderá ler e escrever se "antes" participar de situações práticas e sociais provocativas e que propiciem aprendizagem.

Vale destacarmos aqui, que o significado das palavras para crianças em diferentes faixas etárias possui também construções diversas. Isto nos mostra que o significado de uma palavra representa, do ponto de vista psicológico, a generalização (VIGOTSKI, 2010). Para o autor, as palavras não se referem a um objeto único, mas a uma classe conhecida e a um grupo de objetos. Desse modo, o significado de toda palavra sempre consiste numa generalização construída de maneira diferente daquela elaborada pelos adultos. A criança ainda não possui as generalizações superiores chamadas conceitos, de modo que para ela a generalização tem um caráter mais concreto, mais visual, mais factual e evidente como no exemplo dos cogumelos vermelhos de bolinhas brancas conhecidos pela criança da creche.

Assim sendo, a criança em diversos níveis de desenvolvimento não possui correspondência perfeitamente adequada às ideias de um adulto. $\mathrm{O}$ que significa que concebe e imagina a realidade circundante e seu meio ambiente de modo distinto. Consequentemente o próprio desenvolvimento do pensamento infantil e a generalização também se ligam à influência do meio sobre a criança (ibidem, 2010).

Vigotski também reconhecia que a maturação do organismo individual é fundamental para os processos de desenvolvimento no percurso do desenvolvimento vital humano. No entanto, atribuiu uma importância fundamental aos processos de aprendizado, na medida em que movimentam e possibilitam os processos internos de desenvolvimento.

Implica afirmar que os processos de aprendizado e desenvolvimento ocupam um papel importante em sua teoria e pressupõe a importância dos processos pedagógicos e, subjacente as implicações para o ensino escolar. É nesse sentido que, na trajetória da aprendizagem enquanto "motor" do desenvolvimento, Vigotski (2007) aponta-nos a escola como um espaço privilegiado para a intervenção intencional, deliberada, planejada e dirigida por meio de procedimentos, assistência, dialogia, apoio... balizados 
em certos parâmetros que têm como objetivo conduzir ao desenvolvimento e construção das funções psicológicas a partir da aprendizagem:

[...] o aprendizado adequadamente organizado resulta em desenvolvimento mental e põe em movimento vários processos de desenvolvimento que, de outra forma, seriam impossíveis de acontecer. Assim, o aprendizado é um aspecto necessário e universal do processo de desenvolvimento das funções psicológicas culturalmente organizadas e especificamente humanas. (Vigotski, 2007, p.61)

Esta posição encaminha o professor e outros atores institucionais para uma atitude de permanente observação e investigação do desenvolvimento do aluno. Num contínuo processo interrelacional, as constantes mudanças das condições históricas configuram fenômenos em movimento e impõem uma atuação ativa a todos os envolvidos na experiência social e educacional.

Nessa perspectiva vale ressaltar que somos constantemente modificados pelas nossas ações, e que na experiência cotidiana sobre cogumelos, sentimo-nos impelidas a pesquisar sobre as suas espécies. Assim, deparamo-nos com informações sobre o cogumelo vermelho com manchas brancas chamado Amanita Muscaria ${ }^{l}$, um fungo natural de regiões do oeste norte-americano, da Europa, da Sibéria e da Ásia, que possui propriedades psicoativas e alucinógenas em humanos. Empregado há mais de 6.000 anos por povos primitivos em rituais religiosos, esta espécie de cogumelo também conhecido como "mata moscas" foi tradicionalmente figurado nas ilustrações de contos infantis de autores famosos como Shigeru Miyamoto (Mario Bros) e Lewis Carroll (Alice no país das Maravilhas). Neste livro, Alice conversa com uma lagarta estendida sobre uma Amanita Muscaria.

Assim sendo, somos levadas a destacar que, ao atentarmos e refletirmos sobre a narrativa das duas crianças e a curiosidade acerca da veracidade sobre a existência ou não de cogumelos vermelhos de bolinhas brancas, evocou em nós a escrita e esta, por sua vez, suscitou pesquisas que confirmam os postulados de Vigotski. O desenvolvimento das nossas reações e a evolução dos nossos conceitos associam-se à história de nossas vidas.

Desse modo, uma das afirmações mais importantes que a psicologia pode ensinar ao educador é que o homem/aluno é um ser em movimento. Uma atividade

\footnotetext{
${ }^{11}$ Amanita muscaria. In: WIKIPÉDIA, 2015. Disponível em:

<https://pt.wikipedia.org/wiki/Amanita_muscaria>. Acesso em: 19 dez. 2015.
} 


\section{Ensino, Saúde e Ambiente - V9 (1), pp. 77-89, Abril, 2016.}

autônoma de um educando, orientada por adultos ou colegas pressupõe a participação ativa da criança numa apropriação dos produtos da cultura e da experiência humana.

Dito de outro modo: conforme os postulados vigotskianos, aprendemos e ensinamos ao mesmo tempo. Segundo Prestes (2012, p. 224) essa atividade denominada obutchenie em russo por Vigotski deveria ser traduzida pela expressão ensinoaprendizagem. Todavia, afirma Prestes (ibidem),

[...] em russo, essa palavra implica uma unidade desses processos e a mera
junção por hífen de duas palavras não transmite a ideia que Vigotski atribui a
ela: uma atividade autônoma da criança que é orientada por alguém que tem a
intencionalidade de fazê-lo. Ou seja, obutchenie implica a atividade da
criança, a orientação da pessoa e a intenção dessa pessoa.

Assim, a nossa experiência com cogumelos brancos ou com o Amanita Muscaria comprova a expressão russa obutchenie e reitera o postulado de Freire (1998, p.25) sobre a íntima relação entre ensinar e aprender: "quem ensina aprende ao ensinar".

\section{Considerações finais}

Nossa intenção no presente trabalho foi pensar sobre fatos do cotidiano da educação infantil e entrelaçá-los com a construção de conceitos espontâneos e científicos numa perspectiva histórico-cultural.

Um estudo de caso acerca de uma cena vivenciada entre a pesquisadora e duas crianças numa creche, levou-nos à reflexão e pesquisa no sentido de compreender como se estabelece a inter-relação entre o aprendizado e desenvolvimento na construção do conhecimento.

Do estudo destacamos primeiramente a relevância de se considerar um conceito não apenas como um conjunto de conexões associativas assimiladas pela memória, todavia como uma ação do pensamento, como nos ensina o aporte teórico de Vigotski. Assim, seguimos refletindo acerca da formação de conceitos espontâneos e científicos a partir da linguagem e da relação com o outro, assinalando a interação social como um espaço privilegiado de construção de sentidos e a linguagem como criação do sujeito.

Nesse sentido, a relação entre o pensamento e a palavra é um processo vivo, fluido e permanente se considerarmos que é a palavra que confere vida ao pensamento, uma vez que desenvolve significados e sentidos.

Destacamos, no entanto, que a perspectiva histórico-cultural tem como base que o desenvolvimento do pensamento acerca do significado das palavras das crianças 


\section{Ensino, Saúde e Ambiente - V9 (1), pp. 77-89, Abril, 2016.}

determina uma nova relação que pode existir entre o meio e os processos individuais de desenvolvimento. Isto significa que cada idade infantil possui funções psicológicas superiores que caracterizam o pensamento tipicamente humano em seu nível de desenvolvimento vital. Por meio da linguagem a criança ordena o real agrupando todas as ocorrências de uma mesma classe de objetos, eventos e situações sob uma mesma categoria conceitual. Assim, esses instrumentos de pensamento nos permitem construir conceitos espontâneos, que servirão como fundamentos para a construção dos conceitos científicos.

$\mathrm{Na}$ experiência da pesquisadora e das crianças diante dos cogumelos brancos, estes objetos reais que cresceram num enorme gramado verde, o mundo foi percebido de forma diferenciada pelo adulto e pelas crianças: para o adulto um conhecimento científico enquanto para a criança apenas um conhecimento espontâneo. Enquanto o conhecimento espontâneo carrega na sua estrutura determinantes de diferentes origens, tais como, a sensorial, a emocional, a afetiva e até mesmo moral, por serem construídos nas relações mediadas pela família, por amigos ou por outros grupos significativos, o conhecimento científico está relacionado com o desenvolvimento dos processos psicológicos superiores, deve ser observado de forma prospectiva, na medida em que os seus conceitos serão internalizados na trajetória acadêmica do educando.

Assim sendo, para Vigotski, os conceitos espontâneos seguem seu caminho para o alto, em direção a níveis maiores de abstração e abrem espaços para os conceitos científicos rumo a uma maior concretude, possíveis graças à escola com seus processos de ensino organizados e sistemáticos.

A cena cotidiana, que ilustra as reflexões que tecemos neste artigo, levou-nos a confirmar que, de fato, há uma unidade no processo de ensinar e aprender, atividade denominada obutchenie em russo por Vigotski e traduzida por Prestes pela expressão ensino-aprendizagem.

Vimos, além disso, que a aprendizagem se processa pela internalização de conceitos construídos socialmente. No caso em destaque, evidenciamos que os conceitos científicos são negociados culturalmente, isto é, o cogumelo vermelho com bolinhas brancas conhecido pela criança mais velha é resultado de uma construção iniciada por um conceito espontâneo e, após a negociação de sentidos trabalhada pelas funções mentais superiores da pesquisadora, alcançamos um conceito científico.

Para concluir, mas sem esgotar outras possibilidades de inferências sobre a experiência que elegemos para refletir neste artigo, destacamos a especial importância 
Ensino, Saúde e Ambiente - V9 (1), pp. 77-89, Abril, 2016.

dos postulados de Vigotski que nos mostram como somos seres marcados pelo movimento (sujeito histórico) e que o aprender e o desenvolver é um processo humano de construção contínua, fluida, todavia, intermitente.

\section{REFERÊNCIAS}

DAVIS, Claudia. OLIVEIRA, Zilma de Moraes Ramos de. Psicologia na Educação. $3^{\text {a }}$ ed. São Paulo: Cortez, 2010.

FREIRE, Paulo. Pedagogia da autonomia: saberes necessários à prática educativa. 9 ed. São Paulo: Paz e Terra, 1998.

JOBIM e SOUZA, Solange. KRAMER, Sonia. O debate Piaget/Vigotski e as políticas educacionais. In: Cadernos de Pesquisa, vol. 77, maio 1991. SP: Fundação Carlos Chagas.

OLIVEIRA, Marta Kohl de, O pensamento de Vigotski como fonte de reflexão sobre a educação. Cadernos Cedes, n.35, Implicações pedagógicas do modelo históricocultural. 1995.

PAPALIA, Diane. FELDMAN, Ruth, Duskin. Desenvolvimento Humano. $12^{\mathrm{a}}$ edição. Porto Alegre, RS, AMGH Editora Ltda., 2013.

PRESTES, Zoia. Quando não é quase a mesma coisa: traduções de Lev Semionovitch Vigotski no Brasil. Campinas, SP: Autores Associados, 2012. (Coleção educação contemporânea).

REGO, Teresa Cristina. Configurações sociais e singularidades: o impacto da escola na constituição dos sujeitos. In: OLIVEIRA, Marta Kohl de. SOUZA, Denise Trento R. REGO, Teresa Cristina (orgs). Psicologia, Educação e as temáticas da vida contemporânea. São Paulo: Moderna, 2002.

VIGOTSKI, Lev Semenovich. Pensamento e Linguagem. $3^{\text {a }}$. ed. Trad. Jeferson Luiz Camargo. São Paulo: Martins Fontes, 1991.

VIGOTSKI, Lev Semenovich. Formação social da mente: o desenvolvimento dos processos psicológicos superiores. $7^{\text {a }}$. ed. Trad. José Cipolla Neto, Luís Silveira Menna Barreto, Solange Castro Afeche. São Paulo: Martins Fontes, 2007. (Psicologia e Pedagogia).

VIGOTSKI, Lev Semenovich. Quarta aula: a questão do meio na Pedologia. Tradução de Márcia Pileggi Vinha. In: Revista Psicologia USP, vol.21, nº 4. São Paulo: USP, 2010. P. 681-701 (Dossiê Vigotski e outros trabalhos). 